Article

\title{
The Influence of Freezing on the Course of Carbonization and Pyrolysis of a Bituminous High-Volatile Coal
}

\author{
Valentina Zubkova * and Andrzej Strojwas \\ The Institute of Chemistry, Jan Kochanowski University, 7 Uniwersytecka Str., 25-369 Kielce, Poland; \\ andrzej.strojwas@ujk.edu.pl \\ * Correspondence: zubkova@ujk.edu.pl or Walentyna.Zubkowa@ujk.edu.pl
}

Received: 11 November 2020; Accepted: 4 December 2020; Published: 8 December 2020

check for updates

\begin{abstract}
The course of thermal behavior of a fresh bituminous high-volatile coal during carbonization and pyrolysis was compared to that of this coal thawed after storage. The research was carried out using the following techniques: X-raying, thermogravimetry/Fourier transform-infrared spectroscopy (TG/FT-IR), extraction, Diffuse Reflectance Infrared Fourier Transform Spectroscopes (DRIFT), Attenuated Total Reflectance (ATR), and SEM. The increase in range of the viscous-liquid state and a decrease in temperature of its appearance were stated along with the formation of a more compact residue at the re-solidification stagtablee for the thawed coal during its carbonization. There is a fourfold reduction in the charge volume. The leakage of bitumen that contains 87 At \% of C atoms from swollen grains and a fourfold increase in the yield of the material extracted from these grains are the proof of a greater plasticization of thawed coal. During the pyrolysis of thawed coal, the yield in volatile products of pyrolysis increases, and the composition of these products changes. The contribution ratio of saturated and unsaturated hydrocarbons, $\mathrm{CO}_{2}$, alcohols, and phenols decreases in the composition of volatile products of thawed coal. It is suggested that the use of freezing during the storage of a freshly mined coal that has a poorer caking ability can improve its plasticization during carbonization.
\end{abstract}

Keywords: freezing; storage; carbonization; change in volume; plasticization; pyrolysis

\section{Introduction}

Some changes in the technological properties of different rank coals take place under the influence of oxidation during their storage [1-3]. Coals as products of coalification of mainly natural leftovers (i.e., as materials of natural origin) can be stored at subzero temperatures in order to slow oxidation. The investigations on changes in technological properties of coals in different seasons conducted by Miroshnichenko et al. [4] suggest that a seasonal decrease in the temperature of coal before coking positively affects the changes in thickness of the plastic layer and coke quality. This gives a reason to suppose that the freezing of coal in winter can improve its technological properties.

Ingram and Rimstidt [5] noticed that the thawing of coal and its further drying lead to its disintegration. The disintegration takes place along with the formation of reactive surface of coal and, in their opinion, facilitate its easier oxidation and weathering. In their research on the thermomechanical behavior of coal during mining with the freezing method, Wang et al. [6] ascertained a substantial increase in its strength as the temperature decreased from 20 to $-15^{\circ} \mathrm{C}$. Tao and Xiong-Gang [7] also noticed that the uniaxial compressive strength and the elastic modulus of coal increase when the temperature of freezing drops. Qin et al. [8] determined the changes of the physical pore and fracture structure of coal and uniaxial compressive strengths, acoustic emissions, and ultrasonic wave velocities 
of coal material that were caused by freezing. However, these authors stated that the extension of freezing time affects the compressive strengths of coal negatively [9]. In their opinion, the extension of freezing time for coals leads to an increase in "cumulative pore volume and the cumulative specific surface areas of pores (besides micropores)" [10]. Cai et al. [11] think that the freezing of coal with liquid nitrogen causes an expansion of microfissures inside of coal and leads to a decrease in the acoustic wave speed and a deterioration in mechanical strength.

It has been known for many years that there are several types of moisture in coals [12]. There were distinguished: free water that is identical with bulk water, bound water that freezes at about $226 \mathrm{~K}$, and finally non-freezable water that never freezes, even at the temperature of $123 \mathrm{~K}$ [13]. Using the differential scanning calorimetry (DSC) technique, Nwaka et al. [14] confirmed the presence of the two types of freezable water in coals- "free water" that freezes at the temperature of $-8{ }^{\circ} \mathrm{C}$ and "freezable bound water" that freezes at the temperature of $-42{ }^{\circ} \mathrm{C}$. Kleinberg and Griffin [15] detected the "residuum of unfrozen water" in coals at the temperature of $-14^{\circ} \mathrm{C}$ with the use of the nuclear magnetic resonance spectroscopy (NMR) technique. Wei et al. [16] stated that during freezing, the "pore water" migrates from the surface inward into the coal grain, because this water freezes first on the surface. The volume expansion of water caused by the change in phase presses the surface water inward into the coal grain. The water in pores freezes with an increase in its volume by $9 \%[17,18]$. The freezing of water in pores can lead to mechanical destruction of the coal material. It is known that the freezing of materials that have macromolecular structures can cause a "mechanical breakdown of macromolecules" [19].

Current research studies on the influence of cyclic freezing/thawing by liquid nitrogen and liquid $\mathrm{CO}_{2}$ applied during the elaboration of mining technology of coal bed methane proved unambiguously that these operations invade the structure, influence petrophysical properties of coal, distribution, and connectivity of pores and fissures, and increase the permeability of coals $[8,17,18,20-22]$. Quin et al. [20] studied the cyclic freezing/thawing of coals of different rank using liquid nitrogen and stated that bituminous coal is less receptive to changes in porosity. However, after 25 freeze-thaw cycles for three coals (lignite, bitumite, and anthracite) with the use of liquid $\mathrm{CO}_{2}, \mathrm{Xu}$ et al. [18] stated that the enhancement ratio of total porosity for butumite is the greatest, and it is the lowest for anthracite. As a result of research connected with thermo-oxidative degradation of freezing-thawing of bituminous coals, Epshtein et al. [23] ascertained a widening of their "combustion interval" and a decrease in "rate of combustion and its activation energy".

Around the world, a general trend of running out of good-caking coal resources is observed. During transportation and storage, the thermoplastic properties of bituminous coals are worsening. The elaboration of innovative technologies of coal bed methane mining during freezing/thawing raises questions about the suitability of thawed coals for further use in the production of metallurgical coke. Therefore, the present work aims at investigation of the influence of freezing of a commercial sample of freshly mined coal on its thermal behavior after thawing along with the determination of such influence in the aspects of (i) changes in the structure of the plastic layer of a thawed high volatile bituminous coal and changes in volume of its carbonized charge; (ii) changes in the yield and composition of the volatile products of pyrolysis of thawed coal; and (iii) changes in the structural chemical parameters of the derivatives from plasticized thawed coal compared to fresh coal.

\section{Materials and Methods}

A commercial sample of a freshly mined high volatile bituminous coal with grain size $<20 \mathrm{~mm}$ was the subject of research. The investigations presented in works [16-18] proved that the changes in frozen material of coal would be caused by freezing of "pore water" that is present in the material of fresh coal and does not depend on sizes of their grains.

The proximate and ultimate analyses of the coal are presented in Table 1. The sample was divided into two parts. One part of the sample was dried to the air-dry state under natural conditions for two days at the temperature of $25^{\circ} \mathrm{C}$, crushed to $<3.0 \mathrm{~mm}$ in size, and averaged. The results of investigation of the thermal behavior of a fresh sample were published in our previous work [24]. Another part of 
the commercial sample of fresh coal was frozen and stored for 10 months in a freezer at the temperature of $-15{ }^{\circ} \mathrm{C}$. After that time, the sample was thawed and subjected to the same operations of drying, graining, and averaging as the fresh sample.

Table 1. The main characteristics of coal.

\begin{tabular}{cccc}
\hline \multicolumn{2}{c}{ Proximate Analysis } & \multicolumn{2}{c}{ Ultimate Analysis } \\
\hline $\mathrm{W}^{\mathrm{a}},[\%]$ & 8.5 & $\mathrm{C}^{\mathrm{a}},[\%]$ & 82.2 \\
$\mathrm{~V}^{\mathrm{daf}},[\%]$ & 33.0 & $\mathrm{H}^{\mathrm{a}},[\%]$ & 4.82 \\
$\mathrm{~A}^{\mathrm{d}},[\%]$ & 7.0 & $\mathrm{~N}^{\mathrm{a}},[\%]$ & 1.36 \\
FSI & 7.0 & $\mathrm{~S}^{\mathrm{a}},[\%]$ & 0.47 \\
$\mathrm{RI}$ & 77 & $\left.\mathrm{O}^{\text {diff }}{ }^{*}\right),[\%]$ & 4.15 \\
\hline
\end{tabular}

FSI: Free Swelling Index; RI: Roga Index; ${ }^{*}$ ): calculated by difference; O [\%] = 100-C-H-N-S-Ad.

Pyrolysis in the thermogravimetry/Fourier transform-infrared spectroscopy (TG/FT-IR) measuring unit. The samples of freshly mined coal and thawed coal with a diameter of particles of $<0.2 \mathrm{~mm}$ were pyrolized in a Q50 thermobalance manufactured by TA Instruments Inc. coupled with a Nicolet iS10 FT-IR spectrometer under a flow of nitrogen of high purity. The gas flow through the oven was $10 \mathrm{~mL} / \mathrm{min}$, and through the transfer line and interface, it was $90 \mathrm{~mL} / \mathrm{min}$. The heating process was carried out to $750{ }^{\circ} \mathrm{C}$ with a heating rate of $4{ }^{\circ} \mathrm{C} / \mathrm{min}$. The differences in deviation of the shape of the thermogravimetric analysis (TGA) curves for mass loss from an average value of two samples (after precisely averaging) did not exceed $\pm 0.42 \%$. The volatile products of pyrolysis were analyzed by a Nicolet iS10 spectrometer equipped with a Thermo Scientific TGA-IR interface. The baseline of the FT-IR spectra of volatile products was corrected. The OMNIC9 software was used to analyze the spectra.

Carbonization. The charges of fresh and thawed samples with markers placed in them were carbonized in a laboratory unit in order to investigate the coke-making process with the use of $X$-raying according to the methodology described in [24]. The coking chamber with coal charge was heated in a laboratory oven with vertical unilateral heating to $950{ }^{\circ} \mathrm{C}$. The heating rate was $4{ }^{\circ} \mathrm{C} / \mathrm{min}$. During heating, the temperature inside the chamber was controlled by thermocouples placed in the coal charge. The changes taking place inside the coal charge were recorded on X-ray pictures. The X-ray pictures were elaborated by the CorelDRAW X4 software with magnification of $1300 \%$. The deviations of measured values in the pictures did not exceed $\pm 0.06 \mathrm{~mm}$. The curves of changes in positions of the markers for the two experiments, which were conducted within a time interval of $24 \mathrm{~h}$, practically coincided. After the temperature of $950{ }^{\circ} \mathrm{C}$ was reached, the coking chamber was removed from the oven and cooled quickly. The coking residue was separated into layers according to the methodology described previously [25].

Extraction. The material of the plastic layer separated from the charge was extracted with a 50:50 mixture of methanol and chloroform using an ultrasonic bath by Bandolin Sonorex. The weight of the samples used for the extraction was $2 \mathrm{~g}$. The extraction was carried out at room temperature. The extraction time was $10 \mathrm{~h}$, and the yield of extraction was determined.

FT-IR investigation. Separated material was examined with the use of the FT-IR technique along with the extracts obtained from it. The plasticized samples of coals were examined using a Diffuse Reflectance Infrared Fourier Transform Spectroscopes (DRIFT). The sample was mixed with KBr in a ratio of 1:20. The spectra were recorded using a Nicolet iS10 spectrometer and a PIKE EasyDiff adapter. The spectra were recorded in the range of 4000-600 1/cm. The number of scans was 64 . The obtained spectra were transformed using the Kubelka-Munk function. Then, baseline correction was performed. For this purpose, the OMNIC9 software was used. The extracts were investigated using a Smart Miracle module with a crystal diamond. The Attenuated Total Reflectance (ATR) technique was applied. The spectra were registered in the range of 4000-600 1/cm, and the number of scans was 32 . The baseline was corrected in order to eliminate the non-specific background. The local optical minima near 2400 and 2000 1/cm were taken into account. 
Analysis using ultraviolet (UV) spectroscopy. The samples obtained by extraction were dissolved in acetonitrile. The solutions obtained were tested using a Jasco V-360 spectrometer. Quartz cuvettes were used during the tests. The UV spectra were recorded in the range of 195-300 nm. The obtained spectra were elaborated by the Jasco Spectra Manager software. The analyzed spectra were normalized at $195 \mathrm{~nm}$.

Research with the use of scanning electron microscope (SEM). The plasticized samples from the zones of the plastic layer were studied by the SEM technique. For this purpose, an electron Quanta 3 D FEG microscope manufactured by the FEI company was used. The investigation was carried out using an accelerating voltage of $5 \mathrm{keV}$ without graphite and gold spraying.

\section{Results and Discussion}

\subsection{A Contrastive Analysis of the Course of Pyrolysis Process of Fresh and Thawed Samples}

Figure 1 presents the curves of mass loss and mass loss rate of fresh and thawed samples depending on the temperature pyrolysis. It follows from Figure 1a that the mass loss of thawed coal is greater than that of the fresh one. The curve of the mass loss rate of thawed coal in Figure $1 \mathrm{~b}$ shows a tendency of shifting of the maximum toward lower temperatures compared to the derivative thermogravimetric (DTG) curve of fresh coal.

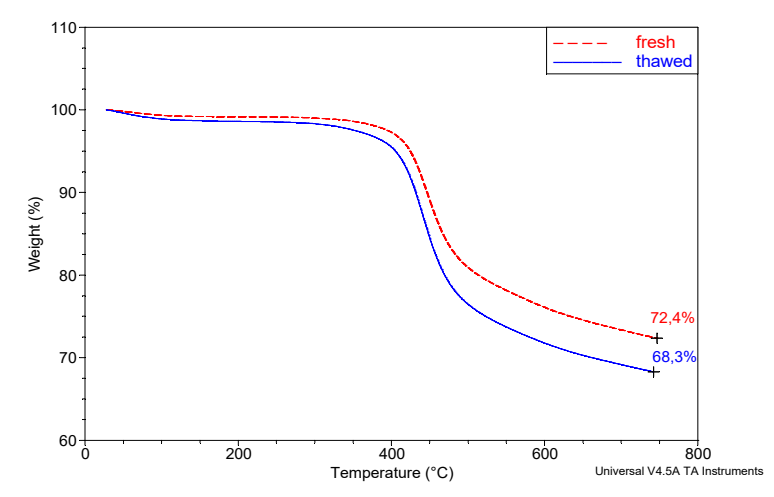

(a)

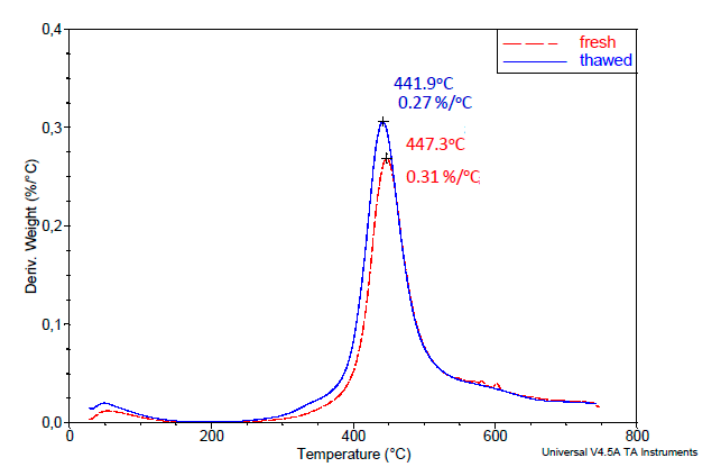

(b)

Figure 1. The curves of mass loss (a) and mass loss rate (b) of fresh and thawed coals depending on the temperature.

The curves in Figure 1 imply that there are more compounds with lower molecular weight in thawed coal than in fresh coal because such compounds are removed from it at lower temperatures. According to the authors [26,27], larger amounts of compounds with low molecular weights present in the plastic mass can facilitate its greater plasticization. In thawed coal, compounds with low mass can be formed as a result of the defragmentation of its macromolecules [19] or as a result of an increase in volume of freezing water in coal pores $[17,18]$. The aforementioned gives reasons to suggest that the changes in shape of the thermogravimetric analysis (TGA) and DTG curves in Figure 1 were caused by the degradation of macromolecules of coal during its freezing. The increase in amount of low-mass compounds in thawed coal implies that these compounds will improve the plasticization of such coal.

\subsection{The Influence of Freezing on the Composition of Volatile Products of Destruction of Fresh and Thawed Coals}

Figure 2 shows the FT-IR spectra of volatile products of destruction of both coals corresponding to the 95th, 100th, 110th, 120th, and 140th min of pyrolysis. The spectra were normalized with regard to the $\mathrm{CH}_{4}$ band. This allowed us to evaluate the content of other components in volatile products directly as their contribution ratio (contribution with regard to $\mathrm{CH}_{4}$ content) further. It follows from the FT-IR spectra in Figure 2 that at the 95 th min of pyrolysis $\left(\mathrm{T}=400{ }^{\circ} \mathrm{C}\right)$, the same contribution 
ratio of saturated and unsaturated hydrocarbons along with an increased contribution of $\mathrm{CO}_{2}$ and water vapor are observed in the composition of volatiles of thawed coal. The $\mathrm{CO}$ band is also present. At the 100th min of pyrolysis $\left(\mathrm{T}=420^{\circ} \mathrm{C}\right)$, in the composition of volatile products of thawed coal, there remains a tendency of greater contribution of water vapor and $\mathrm{CO}_{2}$; the $\mathrm{CO}$ band is also present, but the contribution ratio of saturated and unsaturated hydrocarbons decreases. Starting from the 110th $\min \left(\mathrm{T}=460^{\circ} \mathrm{C}\right)$, in the composition of volatile products of thawed coal, the contribution ratio of $\mathrm{CO}_{2}$ and saturated and unsaturated hydrocarbons decreases, and the contribution ratio of water vapor is the same as for fresh coal.

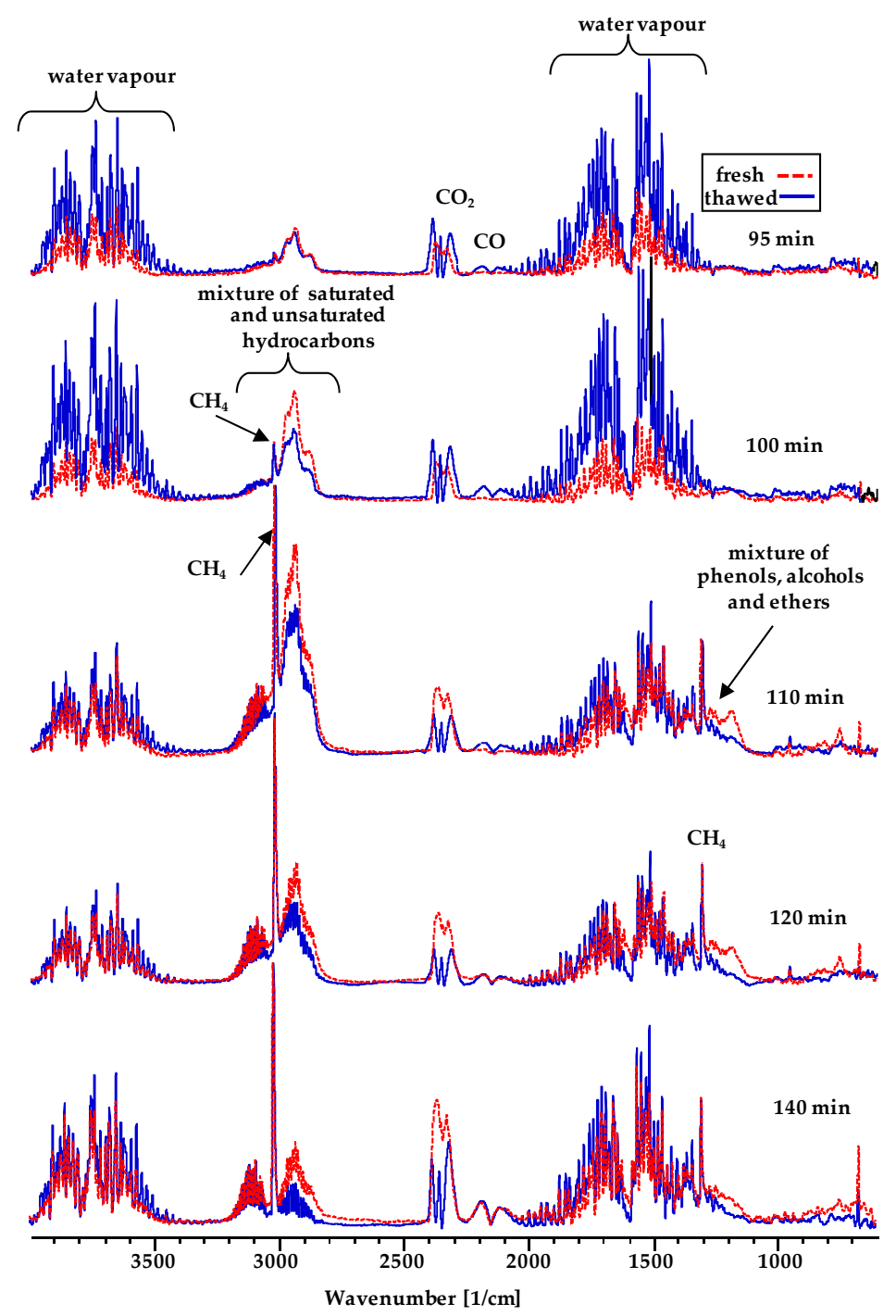

Figure 2. The Fourier transform-infrared spectroscopy (FT-IR) spectra of volatile products of destruction of fresh and thawed coals.

In contrast to fresh coal, in the volatile products of thawed coal, there were no alcohols and phenols registered after the 100th min of pyrolysis. The FT-IR spectra displayed in Figure 2 imply that a decrease in the contribution ratio of saturated and unsaturated hydrocarbons observed in the composition of volatile products can be caused by their remaining in non-volatile residue. This can take place because the processes of mechanical destruction of organic material during sample freezing cause the formation of radicals. The formed radicals can undergo re-combination during pyrolysis and create molecules with greater mass that, in their turn, can cause a greater plasticization of thawed coal. 
An increased contribution of water vapor in volatile products of pyrolysis of thawed coal suggests a simultaneous course of the reaction of condensation between the formed fragments of macromolecules. The presence of $\mathrm{CH}_{4}$ and $\mathrm{CO}$ in the composition of volatile products of thawed coal can facilitate the reactions of conversion of these compounds with water vapor, which leads to the formation of additional amounts of hydrogen, the presence of which is not visible in the FT-IR spectra. Nevertheless, these amounts of transferable hydrogen can terminate the radicals being formed, participate in the reactions of hydrogen disproportionation, and facilitate an increase in the plasticization degree of thawed coal.

\subsection{The Influence of Freezing on the Course of Carbonization of Studied Coal}

Figure $3 \mathrm{a}, \mathrm{b}$ present a comparison of X-ray images of the heated charges of fresh and thawed coal samples. It follows from the X-ray images that there appears a wide dark band (Figure $3 \mathrm{~b}$ ) in the plastic layer of the charge of thawed coal. This shows that a foam-like zone saturated with gases is formed in its plastic layer. Coal transits into the viscous-liquid state in this zone. Such a dark band was not observed in the plastic layer of fresh coal (Figure 3a). In the charge of fresh coal, there is a zone of weakened density formed by grains that are swollen and pressed into each other. The temperature on the edges of the gas-saturated zone $\left(420\right.$ and $470{ }^{\circ} \mathrm{C}$ in Figure $\left.3 \mathrm{~b}\right)$ that is lower in comparison with the temperature on the edges of the weakened zone $\left(455\right.$ and $485^{\circ} \mathrm{C}$ in Figure 3a), which implies that the freezing facilitates a greater plasticization of thawed coal during its carbonization.

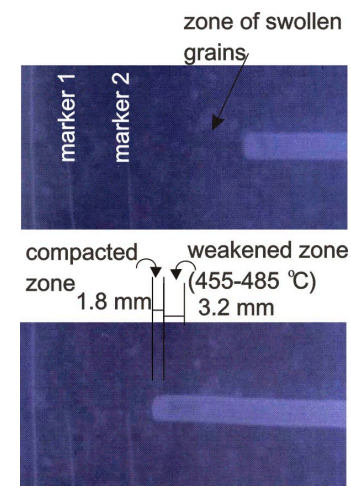

(a)

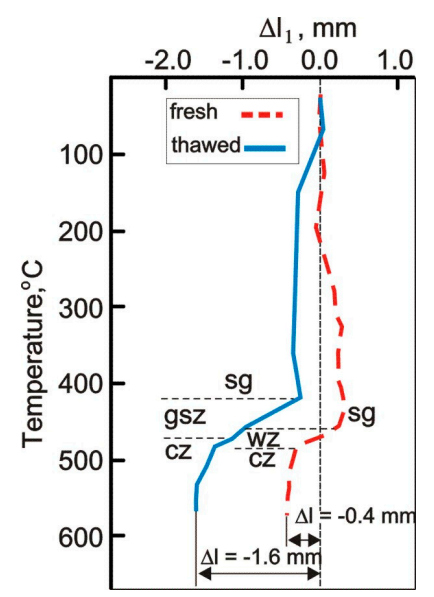

(c)

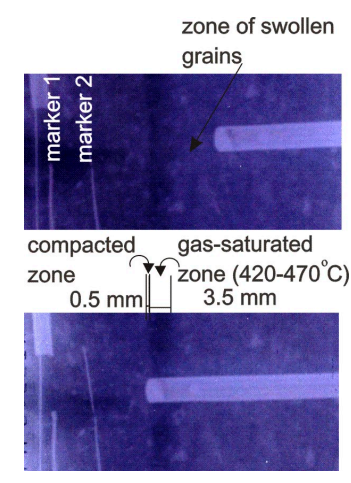

(b)

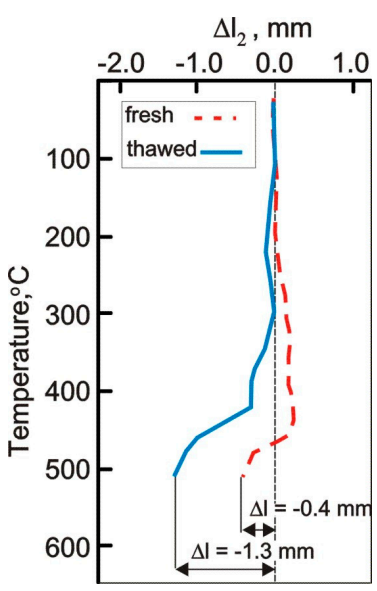

(d)

Figure 3. X-ray images of heated charges of fresh (a) and thawed (b) coals along with the changes in position of marker 1 (c) and marker 2 (d) in the heated coal charges; sg-swollen grains, wz-weakened zone, gsz-gas-saturated zone, cz-compacted zone. 
Figure $3 c, d$ display the curves of changes in positions of markers depending on the temperature. These curves reflect the changes in volume of the carbonized charge between the marker and heating wall. The charge of thawed coal does not show any increase in volume at the stage of grain swelling. There is a substantial drop in volume decrease observed in the temperature range of the viscous-liquid state in the gas-saturated zone of thawed coal. This drop implies the moving of plastic mass toward the heating wall and its densification in the compacted zone. The curves of changes in the position of the marker at the temperatures of re-solidification $\left(\mathrm{T}=550{ }^{\circ} \mathrm{C}\right.$ in Figure $\left.3 \mathrm{c}\right)$ point out an almost fourfold greater reduction of the volume of the charge of thawed coal compared to that of fresh coal. This suggests that a carbonized residue with a greater density is formed from thawed coal during carbonization.

3.4. The Yield of Material Soluble in a Methanol-Chloroform Mixture Obtained from the Material of the Zones of Plastic Layer along with Its Characteristics

It follows from the data in Table 2 that the amount of "mobile phase" extracted from thawed coal at the stage of swollen grains is about four times higher, and in the gas-saturated and compacted zones, it is two times higher than that of fresh coal. The existence of a dependency between the yield of extracted material and its caking ability and plasticizing ability was reported in works [26-28]. It can be concluded on the basis of the increase in yield of extracted material from the zones of the plastic layer and the decrease in temperature on the edges of the gas-saturated zone that the freezing promotes a greater plasticization of thawed coal.

Table 2. The yield of the material extracted from the zones of plastic layer.

\begin{tabular}{cccc}
\hline Sample. & Zone of Swollen Grains & Weakened/Gas-Saturated Zone & Compacted Zone \\
\hline fresh & $0.62 \pm 0.03$ & $0.72 \pm 0.05$ & $0.41 \pm 0.04$ \\
thawed & $2.69 \pm 0.02$ & $1.46 \pm 0.05$ & $0.83 \pm 0.04$ \\
\hline
\end{tabular}

Figure 4 displays the UV spectra of the extracts from the zones of the coal plastic layer. It follows from the comparison of spectra that in the composition of extracts from thawed coal, the concentration of compounds with chromophore groups is much lower than that of fresh coal.

In the extracts from the zone of swollen grains of thawed coal near $225 \mathrm{~nm}$ (Figure 4), the absorbance of peaks corresponding to the occurrence of unsaturated compounds that contain carbonyl groups, cyclic dienes, and aromatic heterocyclic compounds [29] is much lower than that from carbonized fresh coal. It follows from a decrease in the number of peaks in the UV spectra that a range of compounds with chromophore groups disappears in the extracts of thawed coals. This can result from the course of reactions between the formed radicals and the particles of unsaturated hydrocarbons, which lead to the formation of particles of higher mass. The formation of such products in a greater amount increases the registered yield of extraction of material from the plasticized thawed coals. The differences in shape of the UV spectra decrease together with a rise of carbonization temperature in the compacted zone (Figure 4).

The differences in composition of the extracts from plasticized samples of fresh and thawed coals are also displayed in the ATR (FT-IR) spectra in Figure 5. It follows from the analysis of spectra (Figure 5) that the extracts from the samples of thawed coal contain more compounds that are able to form hydrogen bonds, but they almost do not differ by the intensity of peaks corresponding to $\mathrm{C}_{\mathrm{al}}-\mathrm{H}$ bond stretching vibrations. Moreover, the contribution ratio of the compounds able to form hydrogen bonds (including the self-associated bonds of $\mathrm{OH} \cdots \mathrm{OH}$ type) increases together with a rise of carbonization temperature. 

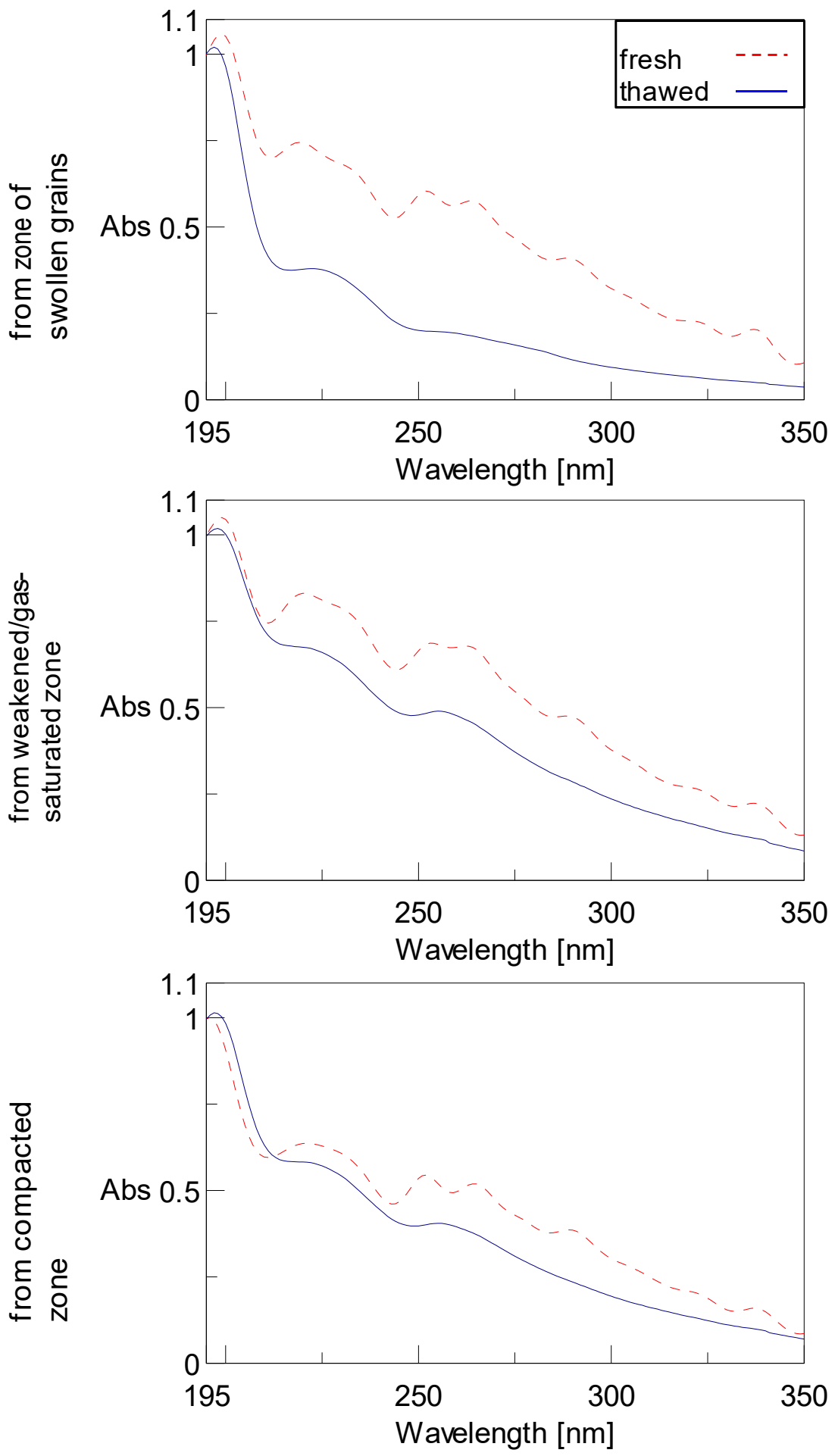

Figure 4. The UV spectra of the extracts from the zones of coal plastic layer: swollen grains, weakened/gas-saturated zone, compacted zone. 


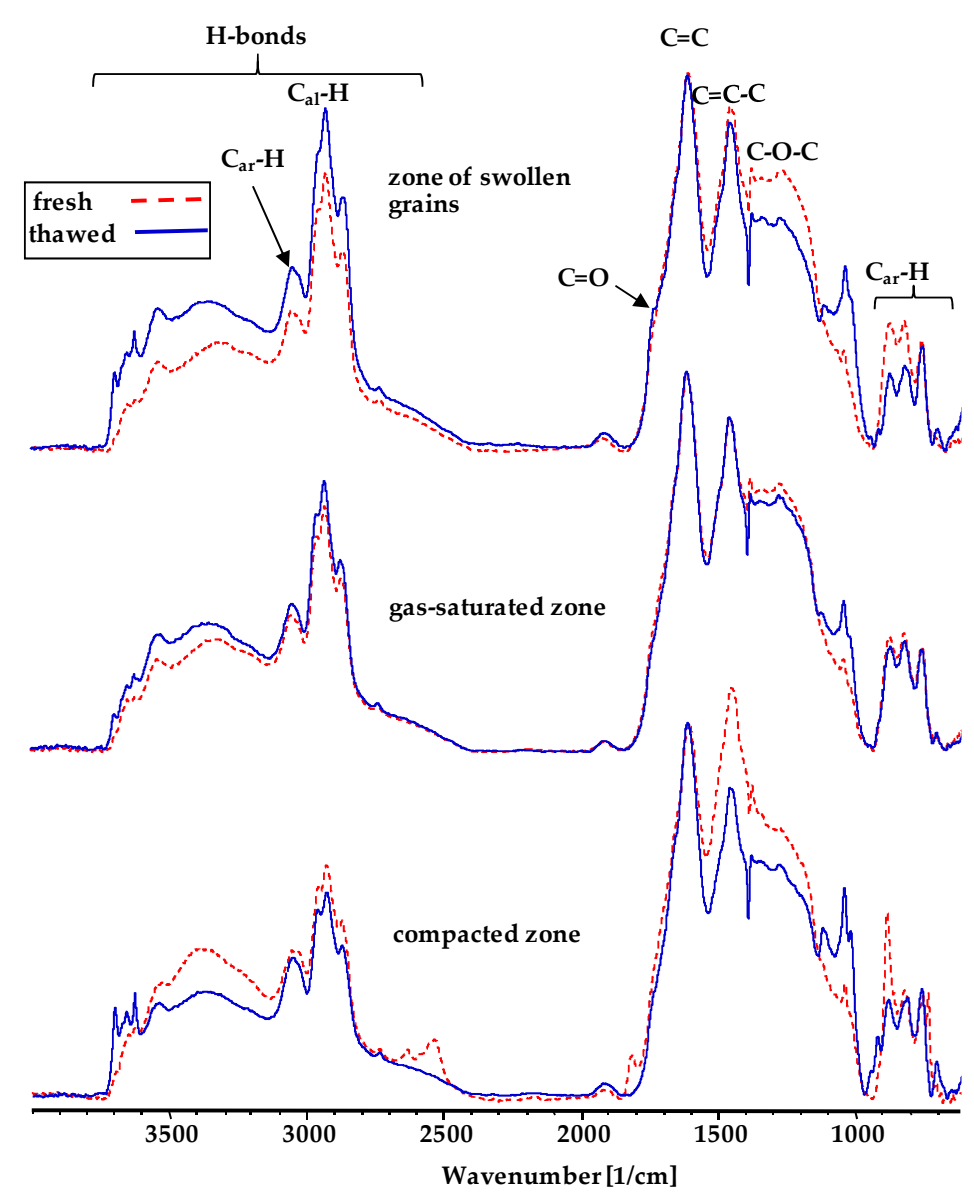

Figure 5. The Attenuated Total Reflectance (ATR) spectra of the material extracted from the zones of plastic layer.

The differences in shape of the spectra appear in the wavenumber range of 1700-1600 1/cm: in the spectra of the extracts from thawed coals, the contribution ratio of the peak corresponding to the presence of carbonyl groups is much lower or disappears (in the viscous-liquid state) in comparison with the extracts from fresh coal. This is also confirmed by the UV spectra in Figure 4, in which a decrease in absorbance in the spectra of extracts implies that carbonyl chromophores disappear. A decrease in contribution ratio of ether bonds (the range of 1300-1150 1/cm) in the extract from the gas-saturated zone points out to a greater degree of plasticization of thawed coal.

\subsection{The Analysis of DRIFT Spectra of Plasticized Coals}

Figure 6 displays the DRIFT (FT-IR) spectra of plasticized coals. In contrast to the tendency observed in the spectra of extracts (Figure 5), in the FT-IR spectra of plasticized samples of thawed coal, the contribution ratio of hydrogen bonds (the wavenumber range of 3680-2400 1/cm) decreases with a rise of carbonization temperature. This decrease relates not only to the bonds of $\mathrm{OH} \cdots \mathrm{OH}$ type but also to the bonds of $\mathrm{OH} \cdots$ OR type. A lower contribution ratio of ether bonds is observed in the plasticized samples from thawed coal. The lack of ether bridges between the fragments of macromolecules can facilitate their mobility. In the wavenumber range of 1100-1000 1/cm, there are some peaks visible that point to an increased contribution of the groups of secondary alcohols and phenols in the plasticized material from thawed coal. This supports the suggestion that some of the low mass compounds (alcohols and phenols) remain in the solid residue of thawed coal without being removed from the carbonized material together with volatile products (Figure 2). 


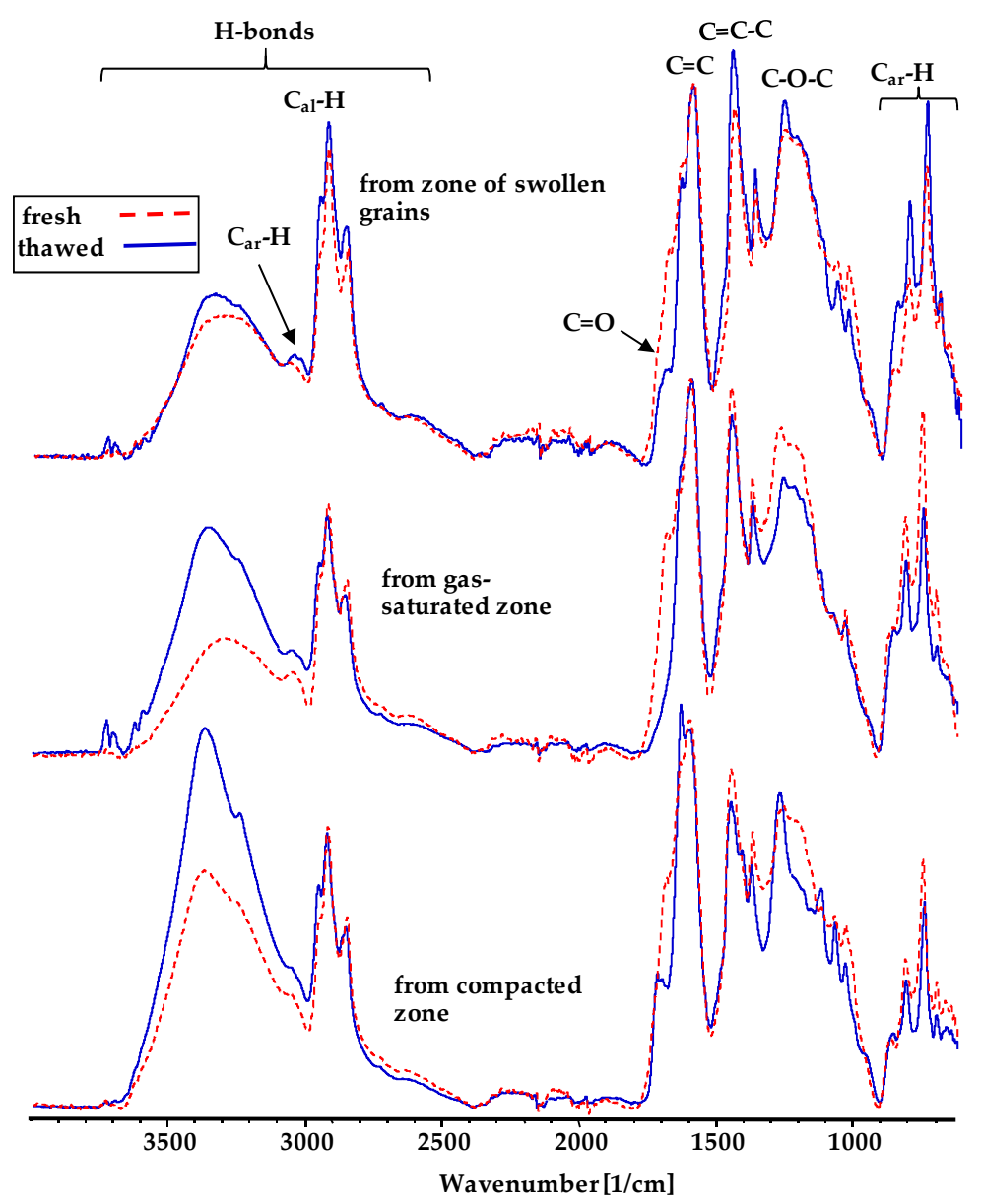

Figure 6. The Diffuse Reflectance Infrared Fourier Transform Spectroscopes (DRIFT) spectra of the material of the zones of plastic layer of fresh and thawed coals.

\subsection{The SEM Images of Plasticized Samples from the Charges of Fresh and Thawed Coals}

Figure 7 presents the SEM images of swollen grains from the charges of fresh (Figure 7a) and thawed (Figure $7 \mathrm{~b}$ ) coals along with the relief of their surface. Attention is drawn to the fact that there are some drops of leaking fluid visible on the surface of swollen grain from the charge of thawed coal (Figure 7b, M300, M3k). There are no such drops on the surface of swollen grain from the charge of fresh coal (Figure 7a, M300). At magnification of M10k, the differences in surface relief of the grains are more distinct. There is a range of rods "growing" from a crack on the grain of thawed coal (Figure 7b). In the cracks of the thawed grain, some material is visible at magnification of M50k (Figure $7 \mathrm{~b}$ ), in which small pores occur. There are no such pores on the surface of the grain from the charge of fresh coal (Figure 7a, M50k). Moreover, some nano-objects were registered in the cracks on the surface of swollen grains of thawed coal (Figure 7c). These objects do not have a definite shape; some rods with a diameter from 60 to $100 \mathrm{~nm}$ come out of them. Another group of objects is made of the aforementioned rods. The dimensions of such rods are as follows: the height is $1260 \mathrm{~nm}$ and the diameter is $314 \mathrm{~nm}$. The presence of these nano-objects does not exclude their probable catalytic influence on the course of plasticization of grains. 

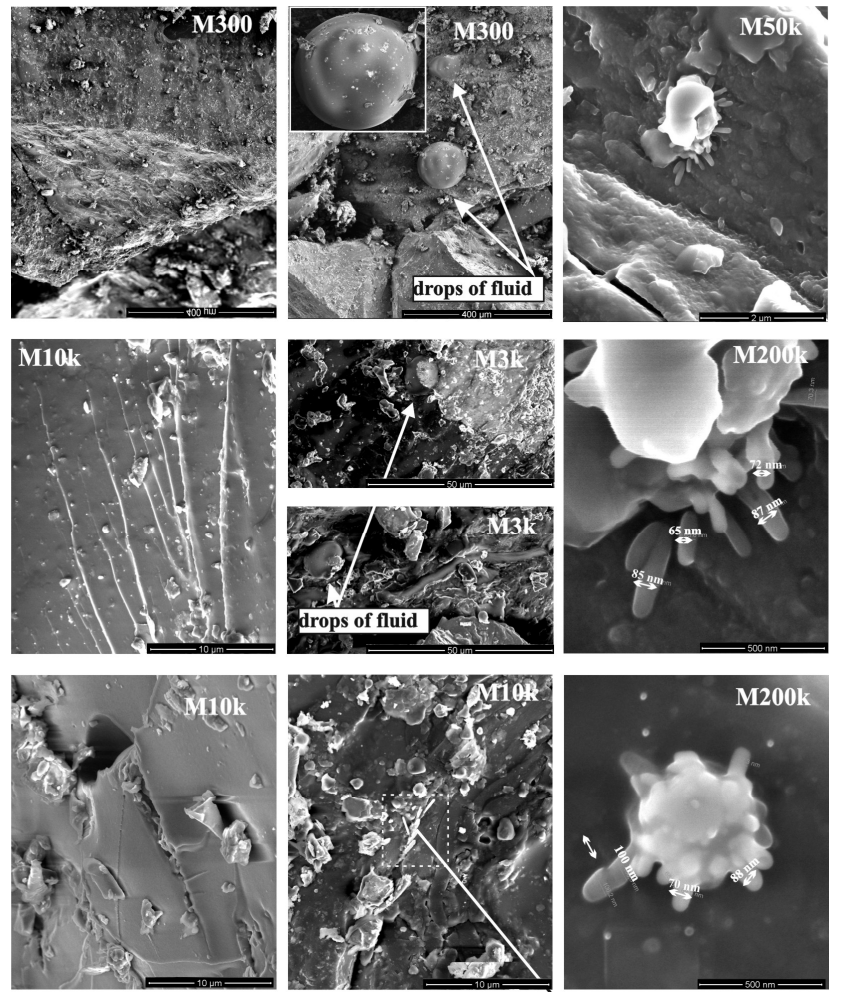

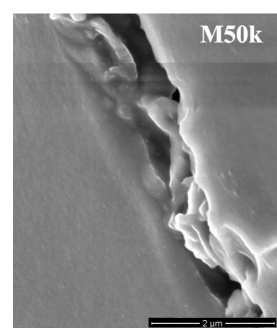

(a)

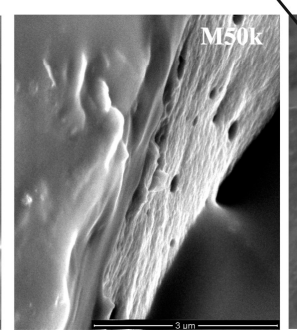

(b)

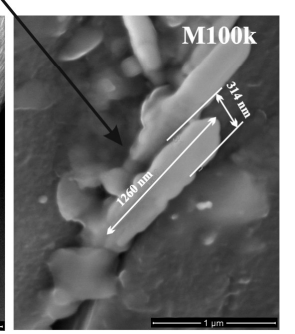

(c)

Figure 7. The SEM images of swollen grains from plastic layer of fresh (a) and thawed (b) coals along with the nano-objects on the surface on swollen grains of thawed coal (c).

The presented SEM images (Figure $7 \mathrm{~b}$ ) indicate clearly that some fluid leaks out from the grains during grain swelling in the charge of thawed coal. According to the data of the EDX analysis, the composition of this fluid is as follows: $87.00 \mathrm{At} \%$ of $\mathrm{C}$ atoms, $11.75 \mathrm{At} \%$ of $\mathrm{O}$ atoms, $0.17 \mathrm{At} \%$ of $\mathrm{Na}$ atoms, $0.32 \mathrm{At} \%$ of $\mathrm{Al}$ atoms, $0.35 \mathrm{At} \%$ of $\mathrm{Si}$ atoms, $0.22 \mathrm{At} \%$ of $\mathrm{S}$ atoms, and $0.19 \mathrm{At} \%$ of $\mathrm{Cl}$ atoms (Figure 8).

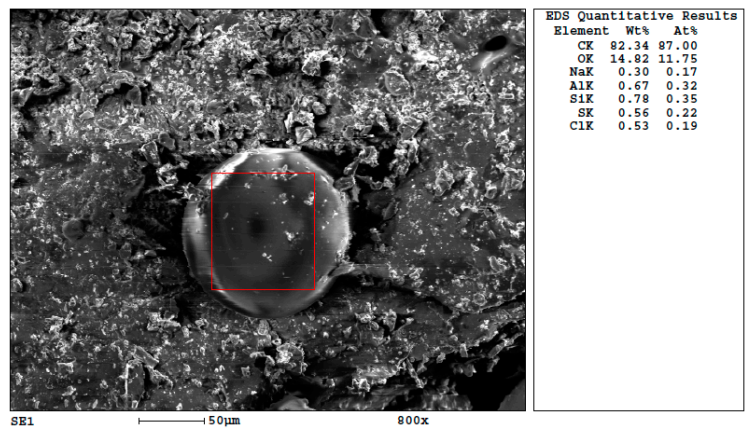

Figure 8. The energy dispersive X-ray (EDX) results of composition of fluid drops. 
These data suggest that the leaking fluid can be the so-called thermobitumen [30] or also "fluid material generated by thermolytic reactions" [31] that was reported as a substance causing coal solvation [32]. The grains containing fluid material show a greater plasticization of thawed coal, which is evidenced by the increase in thickness of the gas-saturated zone in the plastic layer of thawed coal (Figure 3) and the shape of the curves of changes in position of markers in its charge, which is characteristic of good-caking coals [25].

The differences of the plasticized material from the gas-saturated zone are visible in the SEM images (Figure 9). In the gas-saturated zone from the charge of thawed coal, the plastic mass has pores of much greater diameters and thinner walls (Figure 9b, M300). Some blown balloons can be observed inside of the pores of plastic mass of fresh coal (Figure 9a, M100k). In case of thawed coal, such balloons occur in the walls of crushed pores (Figure 9b, M10k, M50k). At a magnification of M100k, the pore wall material of the gas-saturated zone of thawed coal shows a greater compactness (Figure 9b, M100k) than the pore wall material of fresh coal (Figure 9a, M100k).
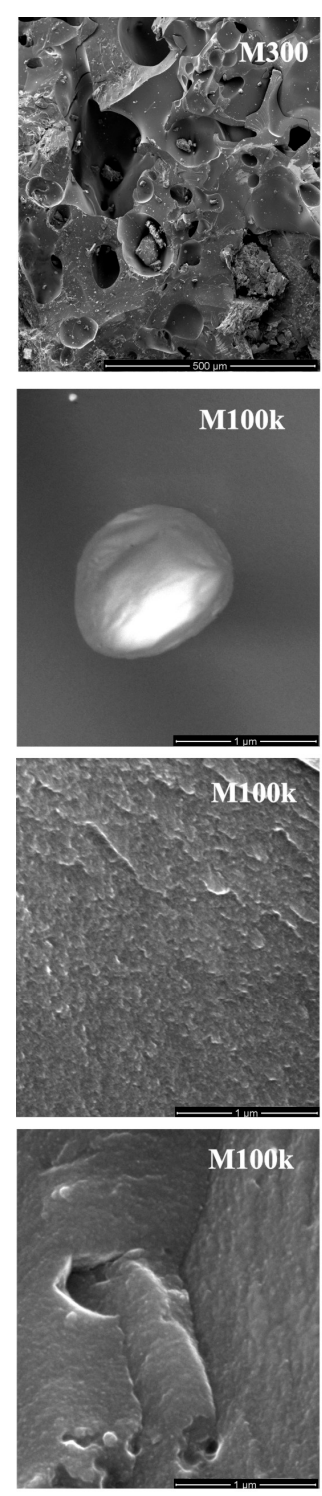

(a)
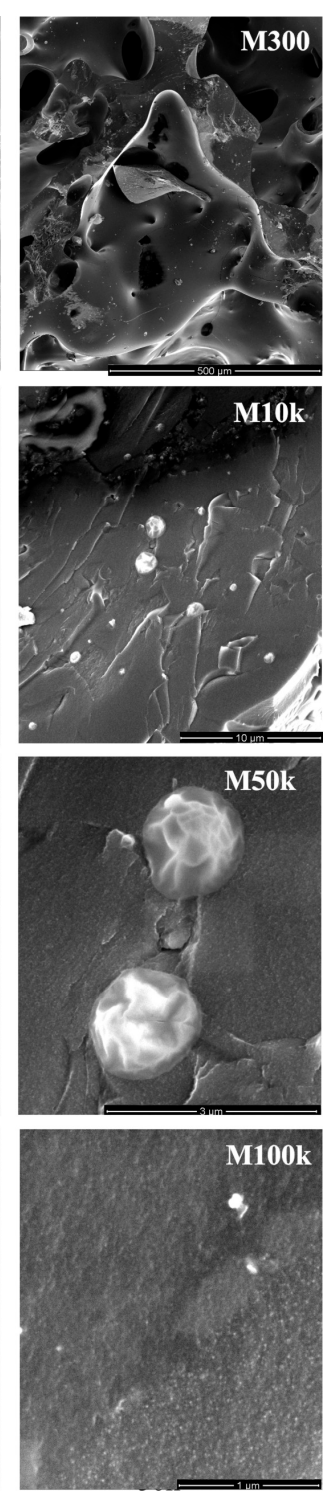

(b)

Figure 9. The SEM images of material from the gas-saturated zones of plastic layer in the charge of fresh (a) and thawed (b) coals. 
In the compacted zone of thawed coal at magnification of M300 (Figure 10b), there are more flattened pores than in the appropriate zone of fresh coal (Figure 10a). At magnification of M6500, it was possible to register this squeezing of the plastic mass into the compacted zone (Figure 10b). Such squeezing was not observed in the compacted zone of fresh coal. The lack of densification of the plastic mass in the compacted zone of fresh coal may have been the reason for a lower compactness of the material in this zone (Figure 10a: M50k, M100k). The material of the compacted zone of thawed coal shows a higher compactness (Figure 10b).
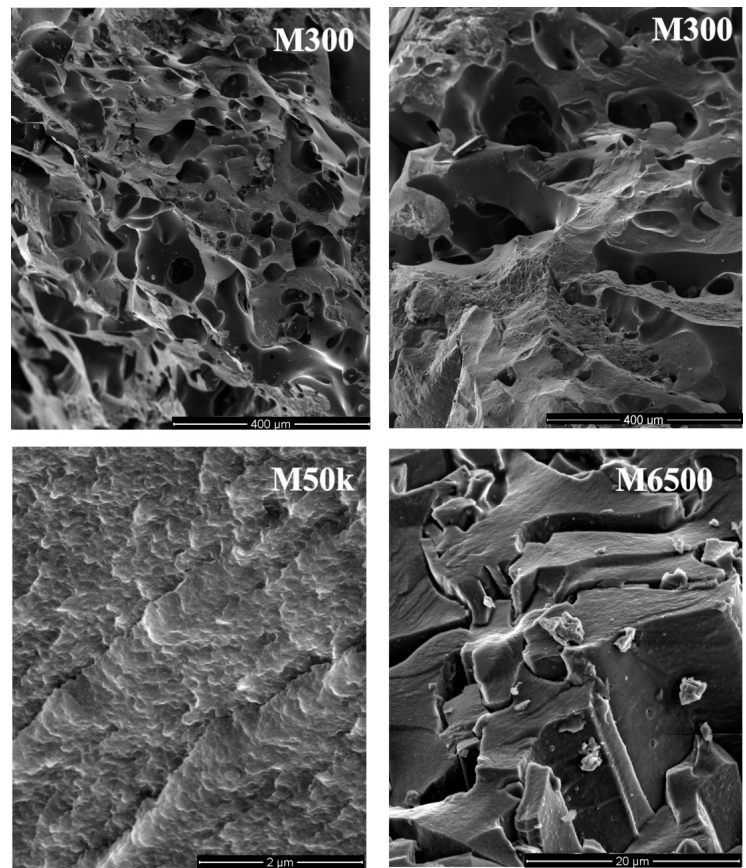

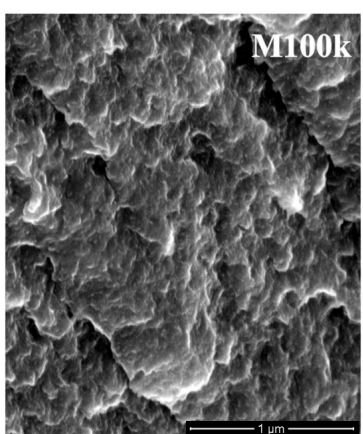

(a)

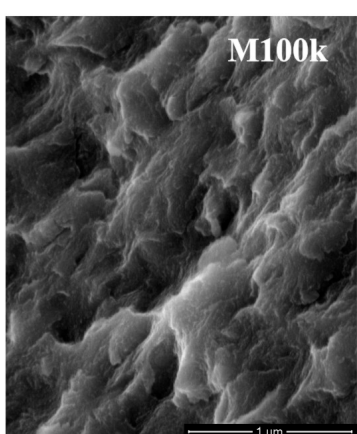

(b)

Figure 10. The SEM images of material from compacted zones of plastic layer in charge of fresh (a) and thawed (b) coals.

\subsection{The Proposed Mechanism of Changes Taking Place during Carbonization of Thawed Coals}

The freezing of wet freshly mined coal will cause an increase in volume of water contained in its pores and lead to the destruction of macromolecules of its organic substance. The radicals (fragments of macromolecules with unpaired electron) that formed as a result of degradation can undergo a mutual re-combination with the formation of smaller macromolecules, and they can be also be terminated by transferable hydrogen $[26,33]$. These reactions will cause an increase in the amount of both volatile products of pyrolysis and products of somehow higher molecular mass that are parts of the so-called "mobile phase". Newly formed products of lower molecular mass that are located at the place of origin (i.e., in the space between macromolecules) can weaken the interaction between 
macromolecules (and their fragments), behave similar to a lubricant [26], and facilitate greater mobility of macromolecules and, hence, a greater plasticization of organic coal substance.

The proof of that includes an increase in the thickness of the gas-saturated zone (Figure 3), the drops of liquid phase leaking out from swollen grains (Figure $7 \mathrm{~b}$ ), and an increase in the yield of the extracts from the zones of the plastic layer of thawed coal (Table 2). It cannot also be excluded that the radicals formed during freezing will react with the compounds containing chromophore groups (for example carbonyl chromophores) and double bonds. The aforementioned reactions will lead to a decrease in the concentration of the compounds containing chromophore groups in the extracts. This effect will result in a reduction of absorbance in the UV spectra for the material extracted from the zones of plastic layer (Figure 4). The formed radicals can promote the reactions of linking to macromolecular chains (extend aliphatic chains [34]) and also initiate the reactions of polymerization of monomers of unsaturated hydrocarbons. Such reactions will lead to the reduction of contribution ratio of saturated and unsaturated hydrocarbons in the composition of volatile products of pyrolysis that are observed in Figure 2.

The obtained data suggest that the observed increase in plasticization degree after the thawing of a weak caking highly volatile bituminous coal can be important in practice. An increasing percentage of weak-caking coal in charge blends frozen in winter will not worsen the quality of produced coke. Ipso facto, it is possible to cut expenses of the raw material loaded into coking chambers. This conclusion needs further and detailed research on the quality of obtained coke.

\section{Conclusions}

The results of the experiment conducted under laboratory conditions proved that the freezing of freshly prepared commercial sample of a highly volatile bituminous coal improves its plasticization degree during carbonization. The temperature of transition in the viscous-liquid state of thawed coal into the viscous-liquid state lowers from 455 to $420^{\circ} \mathrm{C}$. On the surface of swollen grains, there appear some drops of leaking fluid (thermobitumen), the thickness of the gas-saturated zone in the plastic layer increases, and the yield of material extracted from the zones of plastic layer also increases. During the pyrolysis of thawed sample, the yield of volatile products increases, and the composition of these products changes. The contribution ratio of saturated and unsaturated hydrocarbons and $\mathrm{CO}_{2}$ decreases in the composition of the volatile products emitted in the plasticity state. The nano-objects growing inward of the cracks on the surface of swollen grains of thawed coal give reasons to suggest that they were formed as a result of chemical deposition during the removal of volatile products from the grain. It cannot be excluded that the formation of these objects could have a catalytic effect on further development of the plasticity of thawed coal.

The evaluation of changes in the volume of the heated charge of thawed coal and the SEM investigation of the material from the compacted zone prove that the formation of semi-coke in the charge of thawed coal takes place under the conditions of a substantial decrease in the volume of the heated charge. There is a fourfold decrease in the charge volume. Hence, a more compacted carbonized material is formed from the thawed sample of studied coal. The presented research proves that coking plants can increase the contribution ratio of weak caking coals in charge blends during the winter period and lower the costs of production.

Author Contributions: Conceptualization, V.Z.; methodology, V.Z.; investigation V.Z. and A.S.; data curation V.Z. and A.S.; resources A.S.; validation A.S.; writing—original draft preparation V.Z.; writing—review and editing V.Z.; project administration V.Z. All authors have read and agreed to the published version of the manuscript.

Funding: This research was funded by [Rector of Jan Kochanowski University in Kielce] grant number [SIGR.RN.20.076. 609.]

Acknowledgments: The authors would like to thank Benedykt, R. Jany from the Marian Smoluchowski Institute of Physics (the Jagiellonian University in Krakow, Poland) for SEM imaging and Mateusz Kaniewski for his assistance during carbonization of coals and spectroscopic examinations.

Conflicts of Interest: The authors declare no conflict of interest. 


\section{References}

1. Cimadevilla, J.L.G.; Alvarez, R.; Pis, J.J. Effect of coal weathering on technological properties of cokes produced at different scales. Fuel Process. Technol. 2005, 86, 809-830. [CrossRef]

2. Wu, M.M.; Robbins, G.A.; Winschel, R.A.; Burke, F.P. Low-temperature coal weathering: Its chemical nature and effects on coal properties. Energy Fuels 1988, 2, 150-157. [CrossRef]

3. Baris, K.; Kizgut, S.; Didari, V. Low-temperature oxidation of some Turkish coals. Fuel 2012, 93, 423-432. [CrossRef]

4. Miroshnichenko, D.V.; Desna, N.A.; Kaftan, Y.S. Oxidation of coal in industrial conditions. 2. Modification of the plastic and viscous properties in oxidation. Coke Chem. 2014, 57, 375-380. [CrossRef]

5. Ingram, G.R.; Rimstidt, J.D. Natural weathering of coal. Fuel 1984, 63, 292-296. [CrossRef]

6. Wang, C.; Li, S.; Zhang, T.; You, Z. Experimental study on mechanical characteristics and fracture patterns of unfrozen/freezing saturated coal and sandstone. Materials 2019, 12, 992. [CrossRef]

7. Feng, T.; Xie, X. An experimental study of the effect of injecting water and freezing on mechanical properties of outburst-prone coal seam. Procedia Earth Plan. Sci. 2009, 1, 560-564. [CrossRef]

8. Qin, L.; Zhai, C.; Liu, S.; Xu, J.; Tang, Z.; Yu., G. Failure mechanizm of coal after cryogenic freezing with cyclic liquid nitrtogen and its influences on coalbed methane exploitation. Energy Fuels 2016, 30, 8567-8578. [CrossRef]

9. Qin, L.; Zhai, C.; Liu, S.; Xu, J. Factors controlling the mechanical properties degradation and permeability of coal subjected to liquid nitrogen freeze-thaw. Sci. Rep. 2017, 7, 1-11. [CrossRef]

10. Qin, L.; Li, S.; Zhai, C.; Lin, H.; Zhao, P.; Shi, Y.; Bai, Y. Changes in the pore structure of lignite after repeated cycles of liquid nitrogen freezing as determined by nitrogen adsorption and mercury intrusion. Fuel 2020, 267, 117214. [CrossRef]

11. Cai, C.; Gao, F.; Yang, Y. The effect of liquid nitrogen cooling on coal cracking and mechanical properties. Energy Explor. Exploit. 2018, 36, 1609-1628. [CrossRef]

12. Lynch, L.J.; Webster, D.S. Effect of thermal treatment on the interaction of brown coal and water: A nuclear magnetic resonance study. Fuel 1982, 61, 271-275. [CrossRef]

13. Norinaga, K.; Hayashi, J.; Kudo, N.; Chiba, T. Evaluation effect of predrying on the porous structure of water-swollen coal based on the freezing property of pore condensed water. Energy Fuels 1999, 13, 1058-1066. [CrossRef]

14. Nwaka, D.; Tahmasebi, A.; Tian, L.; Yu, J. The effects of pore structure on the behavior of water in lignite coal and activated carbon. J. Colloid Interface Sci. 2016, 477, 138-147. [CrossRef]

15. Kleinberg, R.L.; Griffin, D.D. NMR measurements of permafrost: Unfrozen water assay, pore-scale distribution of ice, and hydraulic permeability of sediments. Cold Reg. Sci. Technol. 2005, 42, 63-77. [CrossRef]

16. Wei, J.; Zhang, L.; Li, B.; Wen, Z. Non-uniformity of coal damage caused by liquid nitrogen freeze-thaw. J. Nat. Gas Sci. Eng. 2019, 69, 102946. [CrossRef]

17. Xu, J.; Zhai, C.; Liu, S.; Qin, L.; Dong, R. Investigation of temperature effects from $\mathrm{LCO}_{2}$ with different cycle parameters on the coal pore variation based on infrared thermal imagery and low-field nuclear magnetic resonance. Fuel 2018, 215, 528-540. [CrossRef]

18. Xu, J.; Zhai, C.; Liu, S.; Qin, L.; Wu, S. Pore variation of three different metamorphic coals by multiple freezing-thawing cycles of liquid $\mathrm{CO}_{2}$ injection for coalbed methane recovery. Fuel 2017, 208, 41-51. [CrossRef]

19. Berlin, A.A. Mechanochemical transformation and synthesis of polymers. Rubber Chem. Technol. 1961, 34, $215-227$. [CrossRef]

20. Qin, L.; Zhai, C.; Liu, S.; Xu, J.; Yu, G.; Sun, Y. Changes in the petrophysical properties of coal subjected to liquid nitrogen freeze-thaw-A nuclear magnetic resonance investigation. Fuel 2017, 194, 102-114. [CrossRef]

21. Zhai, C.; Qin, L.; Liu, S.; Xu, J.; Tang, Z.; Wu, S. Pore structure in coal: Pore evolution after cryogenic freezing with cycling liquid nitrogen injection and its implication on coalbed methane extraction. Energy Fuels 2016, 30, 6009-6020. [CrossRef]

22. Qin, L.; Zhai, C.; Liu, S.; Xu, J.; Wu, S.; Dong, R. Fractal dimensions of low rank coal subjected to liquid nitrogen freeze-thaw based on nuclear magnetic resonance applied for coalbed methane recovery. Powder Technol. 2018, 325, 11-20. [CrossRef] 
23. Epshtein, S.A.; Shkuratnik, V.L.; Kossovich, E.L.; Agarkov, K.V.; Nesterova, V.G.; Gavrilova, D.I. Effects of cyclic freezing and thawing of coals at their behavior at low- and high-temperature oxidation. Fuel 2020, 267, 117191. [CrossRef]

24. Zubkova, V.; Strojwas, A.; Kaniewski, M.; Ziomer, S.; Indyka, P. Some aspects of influence of the composition of volatile products and extracted material on grain swelling processes and volume changes of commercial coals of different rank. Fuel 2019, 243, 554-568. [CrossRef]

25. Zubkova, V. Some peculiarities of formation mechanism of metallurgical coke from Polish coals. Fuel 2004, 83, 1205-1214. [CrossRef]

26. Kidena, K.; Murata, S.; Nomura, M. Studies on the chemical structural change during carbonization process. Energy Fuels 1996, 10, 672-678. [CrossRef]

27. Stanger, R.; Borrowdale, J.; Smith, N.; Xei, W.; Tran, Q.A.; Lucas, J.; Wall, T. Changes in solvent-extracted matter for heated coal during metaplast formation using high-range mass spectrometry. Energy Fuels 2015, 29, 7101-7113. [CrossRef]

28. Shui, H.; Zheng, M.; Wang, Z.; Li, X. Effect of coal soluble constituents on caking property of coal. Fuel 2007, 86, 1396-1401. [CrossRef]

29. Rao, C.N.R. Ultra-Violet and Visible Spectroscopy. Chemical Applications; Copyright for the Polish edition by PWN; Butterworth and Co (Publishers) LTD: Warsaw, Poland, 1982; pp. 99-106. First published 1975, pp. 58-62.

30. Jasienko, S.; Gierus-Piasecka, I. Properties and structure of group components separated from vitrites of coking coals by selective thermosolvolysis. Fuel 1982, 61, 557-564. [CrossRef]

31. Maroto-Valer, M.M.; Andresen, J.M.; Snape, C.E. Quantification by in situ n.m.r. of the contributions from pyridine-extractables and metaplast to the generation of coal plasticity. Fuel 1997, 76, 1301-1308. [CrossRef]

32. Lynch, L.J.; Webster, D.S.; Sakurovs, R.; Barton, W.A.; Maher, T.P. The molecular basis of coal thermoplasticity. Fuel 1988, 67, 579-583. [CrossRef]

33. Lee, S.; Mahoney, M.; Yu, J. Advances in the understanding of the formation and chemistry of the plastic layer during coke-making: A comprehensive review. Fuel 2020, 263, 116655. [CrossRef]

34. Qiu, S.; Zhang, S.; Wu, Y.; Qiu, G.; Sun, C.; Zhang, Q.; Dang, J.; Wen, L.; Hu, M.; Xu, J.; et al. Structural transformation of fluid phase extracted from coal matrix during thermoplastic stage of coal pyrolysis. Fuel 2018, 232, 374-383. [CrossRef]

Publisher's Note: MDPI stays neutral with regard to jurisdictional claims in published maps and institutional affiliations.

(C) 2020 by the authors. Licensee MDPI, Basel, Switzerland. This article is an open access article distributed under the terms and conditions of the Creative Commons Attribution (CC BY) license (http://creativecommons.org/licenses/by/4.0/). 